\title{
Alkaline phosphatase activity in marine oligotrophic environments: implications of single-substrate addition assays for potential activity estimations
}

\author{
Marta Sebastián $^{1, *}$, F. Xavier Niell ${ }^{2}$ \\ ${ }^{1}$ Centro Oceanográfico de Málaga, Instituto Español de Oceanografía, PO Box 285, Fuengirola, Málaga, Spain \\ ${ }^{2}$ Departamento de Ecologia, Facultad de Ciencias, Universidad de Málaga, 29071 Málaga, Spain
}

\begin{abstract}
Measurements of potential enzyme activities are usually carried out to compare enzymatic activity between different systems and minimise the effect of product inhibition or substrate depletion during the assay. There is a general practice of estimating potential alkaline phosphatase activity (APA) using single-substrate addition in excess of saturation, as complete kinetic experiments are time-consuming. Here, complete APA kinetic experiments were carried out in the Subtropical North Atlantic Ocean using from 0.1 to $100 \mu \mathrm{M}$ concentration of the fluorogenic substrate MUF-P. There was a reduction of the velocity of reaction by excess of substrate in all experiments carried out $(n=7)$. This reduction could be related either to inhibition processes, to quenching effects, or to a loss of fluorescence of the product of reaction due to some kind of biological transformation. Moreover, the substrate concentration above which activity diminished was different between the cases studied. Therefore, there was only a narrow range of concentration in which single-substrate addition experiments would have given results comparable to the maximum enzyme activity, and this range differed between stations. Hence, in order to estimate APA potential activities in marine oligotrophic environments, complete kinetic experiments should be carried out, since the use of single additions in excess of substrate may give erroneous results. This conclusion may be extendable to other commonly performed assays of hydrolytic activities in aquatic environments that also use MUF-substrates.
\end{abstract}

KEY WORDS: Alkaline phosphatase activity $\cdot$ Exoenzyme $\cdot$ Potential assays $\cdot$ Marine environments

\section{INTRODUCTION}

The importance of microbial enzymatic activities to the mobilisation, transformation and turnover of organic and inorganic compounds in aquatic environments has been proved over the last 20 yr (e.g. Hoppe 1983, Chrôst et al. 1990, Cotner \& Wetzel 1991). Alkaline phosphatases (AP) are extracellular enzymes that hydrolyse phosphate groups from certain organic phosphorus compounds: monophosphate esters. The activity of these enzymes is usually assayed either fluorometrically or photometrically with monoester phosphate analogues such as MF-P (3-o-methylfluorescein phosphate, e.g. Perry 1972, 1976, Thingstad et al. 1993), MUF-P (4-methylumbelliferyl phosphate, e.g. Hoppe 1983, Ammerman \& Glover 2000) and p-NPP (paranitrophenyl phosphate, e.g. Reichart et al. 1967, Berman 1970, Li et al. 1998). When the enzyme hydrolyses the substrate, equal amounts of orthophosphate and fluorescent (or coloured) nonphosphate moiety are produced, and the assay follows the increase in fluorescence (or colour) over time. 
Fluorogenic artificial substrates have been considered useful and sensitive tools for examining enzyme activity in aquatic environments (Hoppe 1983, Jannson et al. 1988, Chrôst 1990). Marine studies of phosphatases using a fluorogenic substrate (MF-P) date back more than 30 yr (Perry 1972). Since the introduction of the fluorescent methylumbelliferyl and related derivatives for studying the significance of exoenzymes in aquatic ecology (Hoppe 1983), MUF-P has become the preferred fluorogenic substrate for environmental alkaline phosphatase activity (APA) studies. It gives lower background fluorescence than MF-P, and it has been reported to present comparable hydrolysis rates to natural occurring substrates and other artificial substrates (Flint \& Hopton 1977, Berman 1988).

Depending on the aim of and the approach to the problem studied, APA can be assayed either at substrate concentrations approximating in situ conditions (near tracer or in situ approach) or at saturating concentrations to estimate potential activities (kinetic approach). Potential phosphatase activity gives an estimate equivalent to the amount of active enzymes, while the in situ approach tries to estimate actual in situ substrate turnover times, reflecting natural occurring conditions.

The use of near-tracer substrate concentrations for APA determination is preferable, as it reflects in situ processes rather than potential ones. However, many authors argue that the potential activity approach has the advantages of minimising both the effects of possible competition of artificial substrate with natural substrates and the effect of product inhibition or substrate depletion during the assay. Moreover, potential activity assays permit comparison of enzymatic activity between different systems, because activity is not further dependent upon substrate concentration, and changes in substrate concentration are therefore not reflected in changes in APA.

The kinetic approach requires rate measurement at low and high substrate concentrations to determine first order (the reaction velocity increases proportionally to the increase in substrate concentration) and zero order (reaction velocity remains constant, not affected by the concentration of substrate) enzyme kinetics.

Measurements of APA kinetics in seawater are scarce (Thingstad et al. 1998, Van Wambeke et al. 2002, Sebastián et al. 2004). Since complete kinetic experiments are time consuming, there is a general practice of measuring APA using substrate concentrations in excess of saturation (Koike \& Nagata 1997, Nausch 1998, Hoppe \& Ullrich 1999, Sala et al. 2001, Zaccone \& Caruso 2002).
Here, we present results obtained from kinetics experiments carried out in the Subtropical North Atlantic Ocean. The aim of this study is to examine the implications that single-substrate addition assays for estimating potential APA may have in oligotrophic environments.

\section{MATERIALS AND METHODS}

Field data were obtained on board the RV 'Hespérides', on cruises Azores 2 (Azores current region, April 1999) and FAX-9908 (Canary Islands region, August 1999). The cruises were carried out within the CANIGO EU project framework. A General Oceanics Mk III CTD was used to obtain vertical profiles of temperature, salinity density and fluorescence. Water samples were collected with 121 Niskin bottles from a rosette sampler attached to the CTD. Chlorophyll and nutrient determination was carried out as described in Mouriño et al. (2002) (Azores 2) and Sebastián et al. (2004) (FAX-9908).

In this paper we show kinetic experiments performed at the chlorophyll maximum level in 4 oligotrophic stations, whose main characteristics are summarised in Table 1.

APA was measured using the fluorogenic substrate methylumbelliferyl phosphate (MUF-P). MUF-P (Sigma) was dissolved in cold sterile artificial seawater and then stored frozen $\left(-20^{\circ} \mathrm{C}\right)$ until use on board. Prior to kinetic experiments, the MUF-P solution was diluted in autoclaved $0.2 \mu \mathrm{m}$ filtered seawater to obtain the working solutions that were subsequently added to the sample to yield final concentrations of 0.1 to $100 \mu \mathrm{M}$.

The methyllumbelliferon (MUF) produced after the assay was detected as increase in fluorescence by using a Shimadzu RF-5301 PC spectrofluorometer. A standard curve with MUF (Sigma) was used to quantify the amount of MUF produced from APA.

Either duplicate autoclaved samples or duplicate zero-time samples for each amount of MUF-substrate added were run as control samples. Incubations lasted for 2 to $3 \mathrm{~h}$.
Table 1. Station location, depth of sampling (depth of the chlorophyll maximum), integrated chlorophyll (from 0 to $150 \mathrm{~m}$ ), and phosphate concentration at the chl maximum level in the stations where kinetic experiments were carried out

\begin{tabular}{|rcccccl|}
\hline Stn & Latitude & Longitude & $\begin{array}{c}Z \\
(\mathrm{~m})\end{array}$ & $\begin{array}{c}\mathrm{Chl} \\
\left(\mathrm{mg} \mathrm{m}^{-2}\right)\end{array}$ & $\begin{array}{r}\mathrm{PO}_{4}{ }^{3-} \\
(\mathrm{nM})\end{array}$ & Site \\
\hline 2 & $28^{\circ} 41^{\prime} \mathrm{N}$ & $22^{\circ} 54^{\prime} \mathrm{W}$ & 65 & 7 & 20 & Azores current region \\
6 & $32^{\circ} 31^{\prime} \mathrm{N}$ & $22^{\circ} 11^{\prime} \mathrm{W}$ & 80 & 21 & 40 & Azores current region \\
36 & $33^{\circ} 03^{\prime} \mathrm{N}$ & $21^{\circ} 16^{\prime} \mathrm{W}$ & 80 & 22 & 20 & Azores current region \\
45 & $27^{\circ} 29^{\prime} \mathrm{N}$ & $1^{\circ} 07^{\prime} \mathrm{W}$ & 50 & 35 & 200 & Canary Islands \\
\hline
\end{tabular}




\section{RESULTS}

An increase in the MUF produced was observed with increasing substrate concentration in both the controls and the regular samples (Fig. 1). The formation of MUF occurred in the control samples either when they were autoclaved (Fig. 1a,b,d) or zero-time controls (Fig. 1c). The concentrated 2 mM MUF-P solution, from which working solutions for substrate additions were prepared, was routinely checked and seldom showed any fluorescence. Thus, it seems that spontaneous non-enzymatic breakdown occurred when adding MUF-P to the seawater samples. This breakdown was proportional to the substrate concentration applied, at least in the range of concentration considered.

To eliminate substrate hydrolysis due to abiotic processes, controls were subtracted from the samples (Fig. 2). APA followed the same overall trend in all cases. At low MUF-P (up to $\sim 0.2 \mu \mathrm{M}$ ) the velocity of MUF production showed an initial linear increase with substrate concentration (first order kinetics). Then the reaction velocity stopped increasing proportionately to MUF-P concentration and followed an asymptotical trend (zero order kinetics). Nevertheless, there is a threshold concentration of MUF-P (that varies between cases) above which MUF production in samples decreased in relation to controls. Therefore, the reaction velocity diminished until becoming zero, or even negative, i.e. there was an apparent disappearance of product at high concentrations of substrate. Same pattern held in every kinetic experiment carried out $(n=7)$.

The range of concentration for which the velocity of reaction was saturated was different between stations (see Fig. 2, inset plots). At Stns 2 and 6 (Fig. 2a,b) the saturation was reached around $5 \mu \mathrm{M}$ of MUF-P, whereas at Stn 36 (Fig. 2c) it was reached slightly before and at Stn 45 (Fig. 2d) reaction velocity became saturated at much lower concentration $(\sim 0.25 \mu \mathrm{M})$.

The upper edge of the range of concentration for which velocity of hydrolysis remained saturated was also variable between stations. Stns 2, 6 and 45 (Fig. 2a,b,d) showed zero order kinetics up to around 60, 50 and $30 \mu \mathrm{M}$ MUF-P respectively, while Stn 36 (Fig. 2c) showed just up to $\sim 10 \mu \mathrm{M}$ MUF-P.

The substrate concentration at which velocity of enzymatic hydrolysis was zero, i.e. only abiotic hydrolysis could be observed, was also different between stations: 100, 70, 20 and $50 \mu \mathrm{M}$ for Stns 2, 6, 36 and 45 , respectively.
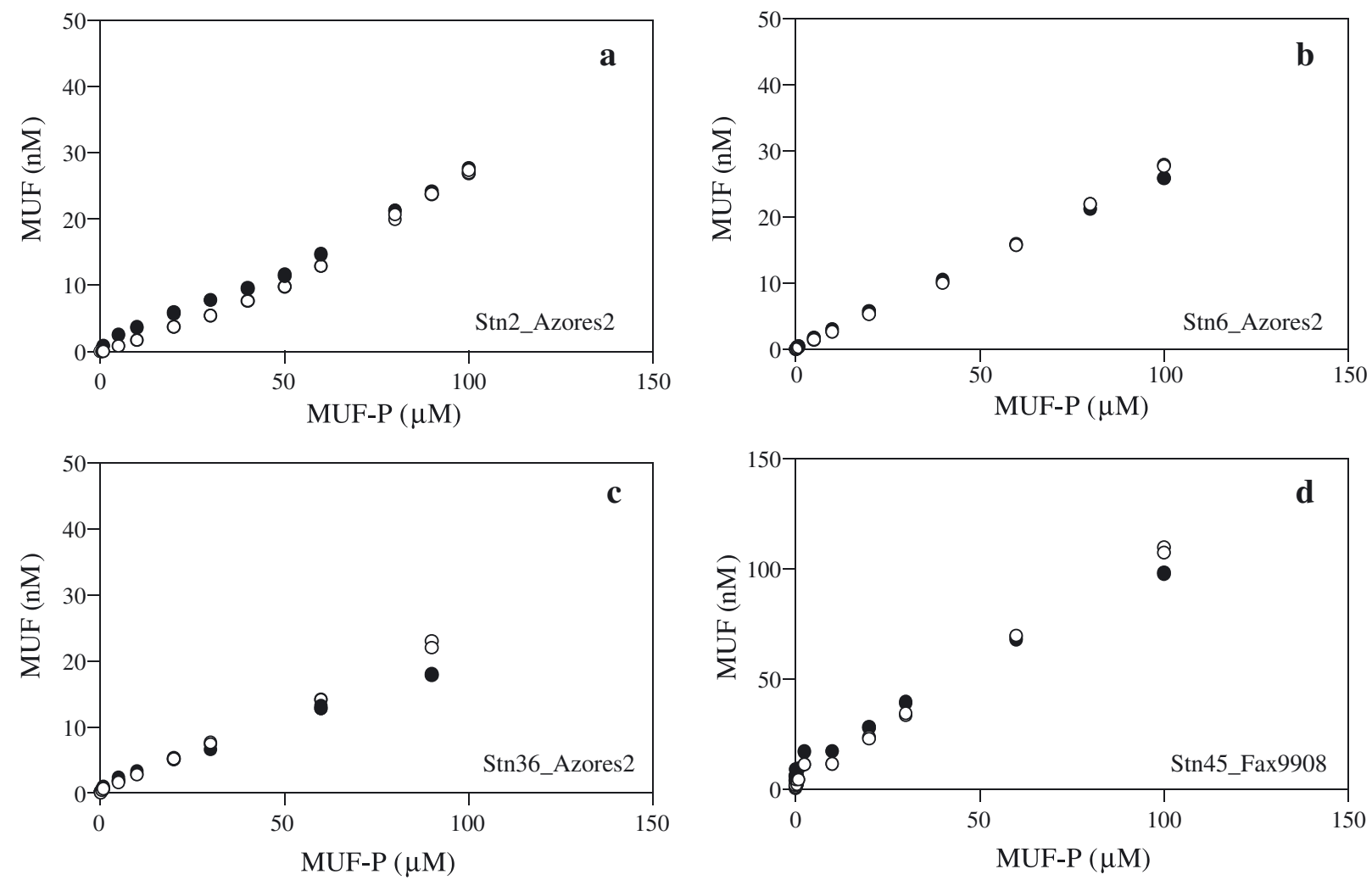

Fig. 1. Concentration of the hydrolysis product (MUF) versus substrate concentration (MUF-P). •: regular samples. O: control samples. Each assay was carried out in duplicate 

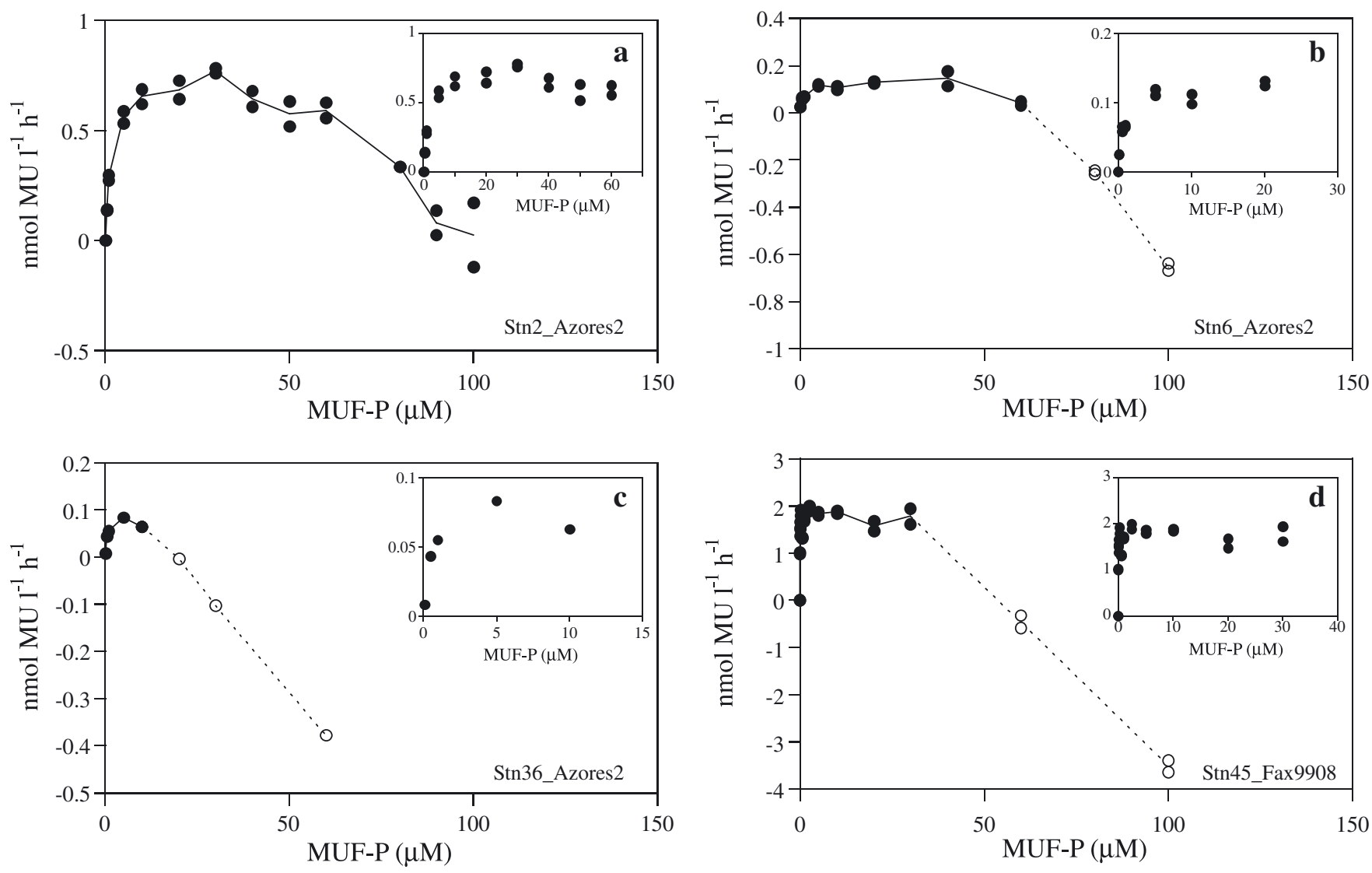

Fig. 2. APA versus substrate concentration (MUF-P). Lines correspond to mean values and dots correspond to replicate values. O: 'negative' values of APA (i.e. when an apparent disappearance of product occurred). Inset: detailed plot in the range of concentration of MUF-P in which first-order and zero-order kinetics could be appreciated. X-scale is different in the inset plots, to underline that the range of concentration for which activity remained saturated was different between stations

\section{DISCUSSION}

Reports on complete APA kinetics in seawater systems are scarce, and limited to the Mediterranean Sea and the North Atlantic Ocean (Thingstad et al. 1998, Van Wambeke et al. 2002, Sebastián et al. 2004). Other studies about APA kinetics have been carried out in fjords (Hoppe 1983, Thingstad et al. 1993).

An apparently spontaneous non-enzymatic hydrolysis of the MUF-P substrate was observed when added to the samples. By contrast, other authors have reported that non-hydrolysed MUF-P presents high background fluorescence (Marxsen \& Witzel 1990). In any case, both observations lead to the conclusion that either to eliminate background fluorescence effects or to ensure that there is no significant substrate hydrolysis due to abiotic processes, control samples for every concentration of substrate added have to be made. If the fluorescence at the beginning of the experiment is assumed to be zero and the fluorescence of the liberated MUF is only measured at the end of the experi- ment, then the enzymatic activity would probably be overestimated. This is particularly important when APA is low.

The decrease in the velocity of reaction of APA at high concentrations of MUF-P could be a result of inhibition of activity by excess of substrate. Marxen \& Witzel (1990) also observed varying degrees of substrate inhibition between 50 and $100 \mu \mathrm{M}$, in a study carried out in sediment samples of small streams. Substrate inhibition of APA has also been reported to occur at substrate concentrations for which $S / K_{\mathrm{M}}>10$, where $S$ is MUF-P concentration and $K_{\mathrm{M}}$ is the Michaelis constant (Fernley \& Walker 1965).

The hypothesis of APA inhibition by excess of substrate is consistent with the fact that the reaction velocity became $100 \%$ inhibited at lower substrate concentrations in the station where APA was lower (Table 2). This pattern held for the Azores 2 cruise. Data are not compared with those obtained in the Fax9908 cruise because both cruises were carried out in different time of the year and in different regions (see 'Materials and methods'). 
Table 2. Maximum potential activity and substrate concentration at which APA activity was reduced to zero in the stations of the Azores 2 cruise (see Fig. 2a-c)

\begin{tabular}{|rcc|}
\hline Stn & $V_{\max }\left(\mathrm{nM} \mathrm{h}^{-1}\right)$ & {$[\mathrm{MUF}-\mathrm{P}](\mu \mathrm{M})$} \\
\hline 2 & 0.69 & 100 \\
6 & 0.13 & 70 \\
36 & 0.07 & 20 \\
\hline
\end{tabular}

But what might be the reason for the apparent disappearance of MUF observed at high substrate concentrations? MUF may have suffered some kind of biological transformation in the field samples that led to a loss of its fluorescence properties. Nevertheless, we cannot discard the occurrence of quenching effects in the measurements. Indeed, one of our anonymous reviewers mentioned that they had observed quenching effects at high concentration of substrate when doing the standard addition method. Quenching may be different in controls and living samples due to the different amount of MUF produced. Since quenching effects can only be detected by the standard addition method, it would be more appropriate to use this method for calibration (internal standards) rather than a standard curve.

As mentioned above, complete kinetic experiments are time-consuming, so the general practice is to examine patterns of enzyme kinetics at the beginning of the experimental series and, afterwards, to carry out one-concentration assays at saturating MUF-P concentration (Nausch 1998, Hoppe \& Ullrich 1999, Cotner et al. 2000, Sala et al. 2001, Zaccone \& Caruso 2002).

Most one-concentration potential assays have been carried out at $200 \mu \mathrm{M}$ MUF-P, or even at higher concentrations (Table 3). However, some authors have encountered saturation of APA at much lower substrate concentrations. Cotner et al. (2000) reported $1 \mu \mathrm{M}$ as a saturating concentration in the Florida Bay. Furthermore, Van Wambeke et al. (2002), in the Mediterranean Sea, carried out complete kinetic experiments in the range of concentration of MUF-P from 0.025 to $1 \mu \mathrm{M}$, and in our study saturation was

Table 3. MUF-P concentration used for potential APA estimations in marine systems by single-concentration assay

\begin{tabular}{|lcl|}
\hline Area of study & $\begin{array}{c}\text { [MUF-P }] \\
(\mu \mathrm{m})\end{array}$ & \multicolumn{1}{c|}{ Source } \\
\hline Central Pacific & $100-150$ & Koike \& Nagata (1997) \\
Baltic Sea & 250 & Nausch (1998) \\
Indian Ocean & 250 & Hoppe \& Ullrich (1999) \\
Florida Bay & 1 & Cotner et al. (2000) \\
Mediterranean Sea & 200 & Sala et al. (2001) \\
N Adriatic Sea & 200 & Zaccone \& Caruso (2002) \\
\hline
\end{tabular}

always found at [MUF-P] $<5 \mu \mathrm{M}$, and sometimes at substrate concentrations as low as $0.25 \mu \mathrm{M}$.

This range of concentration is closer to ambient levels of DOP and POP in seawater, which are usually $<0.5 \mu \mathrm{M}$ (Vidal et al. 1999, Cañellas et al. 2000) and are not likely to reach values up to $200 \mu \mathrm{M}$.

Because of the inhibition and/or the quenching effects, there was only a narrow range of concentrations in which experiments using only one concentration would have given results comparable to the maximum enzymatic activity, and this range varied between stations. In all experiments performed $(n=7)$ the velocity of reaction decreased sharply until reaching zero at $<100 \mu \mathrm{M}$ MUF-P. This means that trying to characterise the maximum enzymatic activity by applying substrate concentration in excess of saturation may give erroneous results, at least in oligotrophic oceanic regions where the scarcity of organisms may lead to low values of activity. Hence, in order to estimate potential activities, complete kinetic experiments should be carried out.

This conclusion may be extendable to other commonly performed assays of hydrolytic enzyme activity in aquatic environments that also use MUF-substrates; therefore, much more effort should be invested in studying the suitability and/or potential problems of generally accepted protocols in different aquatic environments.

Acknowledgements. This work was funded through the European Union (project CANIGO, MAS3.CT96-0060). We thank the officers and crew of the RV 'Hespérides', as well as the staff of the UTM (CSIC) for their invaluable help at sea. M.S. was additionally supported by a FPI/FSE fellowship from the Instituto Español de Oceanografía during the elaboration of the manuscript. She acknowledges T. Ramírez and D. Cortés for their help and supervision. We also wish to thank the anonymous referees, who helped us improve the paper.

\section{LITERATURE CITED}

Ammerman JW, Glover WB (2000) Continous underway measurement of microbial ectoenzyme activities in aquatic ecosystems. Mar Ecol Prog Ser 201:1-12

Berman T (1970) Alkaline phosphatases and phosphorus availability in Lake Kinneret. Limnol Oceanogr 15:663-674

Berman T (1988) Differential uptake of orthophosphate and organic phosphorus substrates by bacteria and algae in Lake Kinneret. J Plankton Res 10: 1239-1249

Cañellas M, Agustí S, Duarte CM (2000) Latitudinal variability in phosphate uptake in the Central Atlantic. Mar Ecol Prog Ser 194:283-294

Cotner JB, Wetzel RG (1991) 5'-Nucleotidase activity in a eutrophic lake and a oligotrophic lake. Appl Environ Microbiol 57:1306-1312

Cotner JB Jr, Sada RH, Bootsma H, Johengen T, Cavaletto JF, Gardner WS (2000) Nutrient limitation of heterotrophic bacteria in Florida Bay. Estuaries 23:611-620

Chrôst RJ (1990) Microbial ectoenzymes in aquatic environ- 
ments. In: Overbeck J, Chrôst RJ (eds) Aquatic microbial ecology: Biochemical and molecular approaches. SpringerVerlag, New York, p 47-78

Fernley HN, Walker PG (1965) Kinetic behaviour of calfintestinal alkaline phosphatase with 4-methylumbelliferyl phosphate. Biochem J 97: 95-103

Flint KP, Hopton JW (1977) Substrate specificity and ion inhibition by bacterial and particle associated alkaline phosphatases of waters and sewage sludges. European J Appl Microbiol 4:195-204

Hoppe HG (1983) Significance of exoenzymatic activities in the ecology of brackish water: measurements by means of methylumbelliferyl-substrates. Mar Ecol Prog Ser 11: 299-308

Hoppe HG, Ullrich S (1999) Profiles of ectoenzymes in the Indian Ocean: Phenomena of phosphatase activity in the mesopelagic zone. Aquat Microb Ecol 19:139-148

Jansson M, Olsson H, Petterson K (1988) Phosphatases: origin, characteristics and function in lakes. Hydrobiologia 170:157-175

Koike I, Nagata T (1997) High potential activity of extracellular alkaline phosphatase in deep waters of the central Pacific. Deep-Sea Res II 44:2283-2294

Li H, Veldhuis MJW, Post AF (1998) Alkaline phosphatase activities among planktonic communities in the northern Red Sea. Mar Ecol Prog Ser 173:107-115

Marxsen J, Witzel KP (1991) Significance of extracellular enzymes for organic matter degradation and nutrient regeneration in small streams. In: Chrôst RJ (ed) microbial enzymes in aquatic environments. Springer-Verlag, New York, p 270-285

Mouriño B, Fernández E, Escánez J, de Armas D, Giraud S Sinha B, Pingree R (2002) A Subtropical oceanic ring of magnitude (STORM) in the Eastern North Atlantic:

Editorial responsibility: Otto Kinne (Editor), Oldendorf/Luhe, Germany physical, chemical and biological properties. Deep-Sea Res II 49:4003-4021

Nausch M (1998) Alkaline phosphatase activities and the relationship to inorganic phosphate in the Pomeranian Bight (southern Baltic Sea). Aquat Microb Ecol 16:87-94

Perry MJ (1972) Alkaline phosphatase activity in subtropical central North Pacific waters using a sensitive fluorometric method. Mar Biol 15:113-119

Reichardt W, Overbeck J, Steubing L (1967) Free dissolved enzymes in lake waters. Nature 216: 1345-1347

Sala MM, Karner M, Arin L, Marrasé C (2001) Measurement of ectoenzyme activities as an indication of inorganic nutrient imbalance in microbial communities. Aquat Microb Ecol 23:301-311

Sebastián M, Aristegui J, Montero MF, Niell FX (2004) Kinetics of alkaline phosphatase activity, and effect of phosphate enrichment: a case study in the NW African upwelling region. Mar Ecol Prog Ser 270:1-13

Thingstad TF, Skjoldal EF, Bohne RA (1993) Phosphorus cycling and algal-bacterial competition in Sandsfjord, western Norway. Mar Ecol Prog Ser 99:239-259

Thingstad TF, Zweifel UL, Rassoulzadegan F (1998) P limitation of heterotrophic bacteria and phytoplankton in the Northwest Mediterranean. Limnol Oceanogr 43:88-94

Van Wambeke F, Christaki U, Giannakourou A, Moutin T, Souvemerzoglou K (2002) Longitudinal and vertical trends of bacterial limitation by phosphorus and carbon in the Mediterranean sea. Microb Ecol 43:119-133

Vidal M, Duarte CM, Agustí S (1999) Dissolved organic nitrogen and phosphorus pools and fluxes in the central Atlantic Ocean. Limnol Oceanogr 44(1):106-115

Zaccone R, Caruso G (2002) Microbial hydrolysis of polysaccharides and organic phosphates in the Northern Adriatic Sea. Chem Ecol 18:85-94

Submitted: January 12, 2004; Accepted: June 15, 2004 Proofs received from author(s): August 9, 2004 